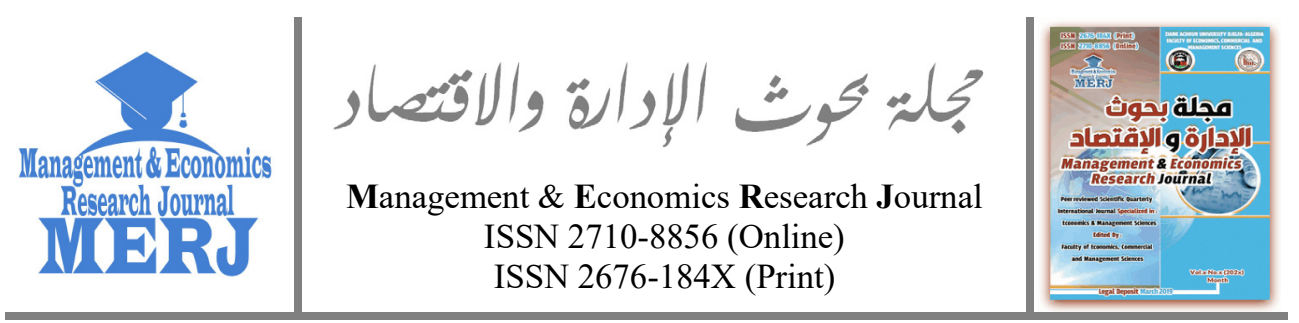

Vol. 4 No. 1 (2022): March, pp. 1-17

https://doi.org/10.48100/merj.2022.172

Check for updates

\title{
Evaluating Starting a Business Indicators Innovation in the World
}

\author{
Antoine Niyungeko ${ }^{1}$ (D) \\ ${ }^{1} \mathrm{PhD}$ in International Entrepreneurship, Independent Consultant, Temporary Teacher, \\ Bujumbura Light University (Burundi) \\ $\bowtie$ niyungantoine@yahoo.fr
}

Received: 26-06-2021

Accepted: 21-09-2021

Published online: 23-09-2021

How to Cite:

Niyungeko, A. (2022). Evaluating Starting a Business Indicators Innovation in the World. Management \& Economics Research Journal, 4(1), 1-17. https://doi.org/10.48100/merj.2022.172

\section{Abstract:}

Since 2003, the World Bank has produced an annual report ranking economies based on ease of doing business score. However, little is known whether the improvements made by evaluated economies on starting business indicators are statistically significant, as claimed by the World Bank. This study aims to evaluate the extent to which starting business indicators were improved in the 145 economies evaluated. The indicators assessed are: starting a business score (SBS), starting a business procedure for men (SBPM), starting a business time for men (SBTM), starting a business cost for men (SBCM), starting a business procedure for women (SBPW), starting a business time for women (SBTW), starting a business cost for women (SBCW), and starting a business in paid-in minimum capital (SBPMC). This study used secondary quantitative data retrieved from the database of the World Bank for the 2004 and 2020 periods. The sample size was made up of 145 economies. Wilcoxon-sign-rank-test-paired-sample was computed using the $\mathrm{R}$ programming environment. The results of the Wilcoxon-sign-rank-test-

- Corresponding author: Bujumbura Light University (Burundi).

[ $\square$ niyungantoine@yahoo.fr]

(C2022 the Author(s). This is an open-access article distributed under the terms of (CC BY-NC 4.0) which permits use, distribution and reproduction in any medium, provided the original work is properly cited and is not used for commercial purposes.

Faculty of Economics, Commercial \& Management
Sciences, Ziane Achour University of Djelfa, BP
3117, Djelfa - Algeria


paired-sample indicated that the mean differences are statistically different from zero for all indicators except those evaluated. This means that the economies evaluated improved those indicators for 2020 compared to 2004. The study's findings provide clear insight to policymakers regarding innovations made to ease of doing business improvement. Better use of the results of this study would reduce corruption and increase formal business, increase the number of newly registered businesses, increase business opportunities for starting a new business, and increase companies' productivity. This study evaluated whether business regulations implemented regarding starting a business were statically significant. Future research should be conducted to empirically test the significance of implemented procedures related to other indicators evaluated in doing business reports. This research is novel by empirically testing innovations made in 145 world economies on starting business requirements.

Keywords: Starting Business, Business Procedures, Business Cost. JEL Codes: M48.

\section{Introduction}

Since 2003, the World Bank (WB) has issued an annual report evaluating how economies improve their business environment. During the evaluation process, the WB considers several indicators directly affecting the ease of business. The first production of this report was inspired by the work of Djankov, La Porta, Lopez-De-Silanes, and Shleifer (2002). These authors investigated data related to the number of procedures, official time, and official costs that a startup must bear before operating legally. They concluded that official costs of entry were extremely high in most countries. Moreover, countries with heavier regulation of entry had higher corruption and larger unofficial economies, nonetheless, the not better quality of public or private goods. Countries with more democratic and limited governments had lighter regulations of entry.

Many studies were conducted to evaluate the impact of regulation on the business environment. For instance, Canare (2018) indicated that starting a business component positively affected business creation in 120 countries examined. Davari and Farokhmanesh (2017) and Farokhmanesh (2017) concluded that legislation positively encouraged startup opportunities. Chambers and Munemo (2019) established a negative correlation between procedures and new business creation. They indicated that entrepreneurial activity decreased between three and seven per cent when the number of steps required to create a new business increased by unit. The WB (2020) indicated improved firm entry regulation correlated with higher productivity. Olagunju 
and Ikeolumba (2019) concluded that even though the policy had recorded some small degree of success, the business climate in Nigeria was still far from friendly due to some implementation inconsistencies that had beclouded the policy objectives.

Even though regulations impact the business environment, to the author's knowledge, no study has been conducted evaluating to what extent starting business components have been improved in the world from 2004 to 2020. The WB claims that starting a business has improved, but there is no/little empirical evidence to support this statement. The WB only reports changes made by countries regarding ten indicators evaluated in doing business reports. However, little is known about whether those changes are statistically significant, as indicated by the WB (2020). These ten economies advanced the most efforts in starting a business, dealing with construction permits, and trading across borders.

Furthermore, significant innovations have been made since 2003/04. As indicated by the WB, 178 economies have executed 722 reforms related to starting a business indicator set, either reducing or eliminating barriers to entry. In all, 106 economies removed or reduced minimum capital requirements; about 80 introduced or improved one-stop shops, and more than 160 simplified preregistration and registration formalities.

This study was organised into five sections. After the introduction, the second section shows a literature review. The third section offers the methods used in the study. Section four presents the result and discussion. Finally, the fifth section represents the conclusion.

\section{Literature review}

\subsection{Theoretical overview}

Many theories have been developed to support the ease of doing business. For instance, transaction cost theory (TCT) recommends that conducting transactions is costly (e.g., discussing contracts, monitoring performance, and solving disputes). That diverse modes of organising businesses involve different costs (Rindfleisch,2019). Therefore, according to this theory, a comparative analysis of the relative business costs of these alternative modes tells how a particular transaction should be led. Based on this theory, a country with high transaction costs cannot attract investors. The TCT has been used in examining firms' limitations, vertical integration choices, the rationale for leading an acquisition, the networks, and other mixture governance forms (Martins, Serra, Leite, Ferreira, and Li, 2010). Another theory that needs to be mentioned is the internalisation theory. 
Internalisation theory examines how the corporation's owners, managers, or trusted establishments make decisions. The hypothesis presupposes that these decisions are rational. In this case, rationality means that the decision-maker can recognise a set of possibilities, has a goal by which these options can be ranked, and can identify and select the highest-ranked choice (Buckley \& Casson, 2009). According to these authors, rational agents internalise markets when the anticipated benefits surpass the estimated costs. In addition to the mentioned theory, an eclectic paradigm can be presented. In the eclectic paradigm, it is assumed that multinational corporations have competitive or ownership advantages vis-à-vis their major competitors, which they exploit in establishing attractive production sites due to their location advantages. Competitive advantage can result from the ownership of particular unique intangible assets (e.g., firm-specific technology) or is due to the ownership of complementary assets (e.g., the ability to create new technologies or the ability to coordinate cross-border activities effectively) (Cantwell \& Narula, 2001). Based on this approach, countries must make their economies attractive to foreign investors. Another theory related to the decision of firm competitive advantage is the theory of the resource-based view (RBV). The RBV emphasises internal resources (e.g., knowledge, physical assets, human capital, and other tangible and intangible factors owned or controlled) and capabilities to detect the determinants of a firm's competitive advantage and performance (Juan, Raquel, and Pedro, 2019). These authors indicated that RBV advises that inter-organisational interactions can allow small and medium-sized enterprises to gain access and availability to tangible and intangible resources that fortify their current resource base, which will affect performance.

The public choice theory clarifies how policymakers' decisions can serve their interest, not the mass. Holcombe (2018) indicated that this theory clarifies how some can use the system for their profit at the cost of others, but it does not classify who those are. He added that the 99 per cent are rationally ignorant and that focused interests can use the political system for their benefit at the expense of the masses. Djankov, La Porta, Lopez-De-Silanes, and Shleifer (2002) indicated that the tollbooth theory explains that regulation is pursued interest of politicians and bureaucrats. These authors indicated that politicians use regulation to generate rents and extract them through campaign contributions, votes, and bribes. Many of these permits and regulations exist mainly to give administrators the power to deny them and to gather bribes in return for the permits. The last theory is the theory of regulatory capture. This theory claims that regulations are routinely and predictably 'captured' and manipulated to work for the interests of those who are supposed to be subject 
to them or the bureaucrats and legislators who write or control them (Etzioni,2009). Politicians acting in the way tollbooth and regulatory capture theories will destroy their economies. They may be characterised by the dark triad, a psychological term explaining individual negative dispositions. Myung and Choi (2017) state that the dark triad is composed of Machiavellianism, which refers to a tendency to manipulate others to gain an advantage; psychopathy, which refers to a general lack of empathy; and narcissism, which refers to excessive self-love.

The objectives of these theories are twofold. First, some support creating a friendly business environment (transaction cost theory). It was shown that an economy with low transaction costs attracts investors. Second, some theories explain the motivation of policymakers (the tollbooth theory, public choice theory, etc.). These theories argue that politicians use regulation for their interests, not for the mass.

Nevertheless, besides the theories that show the dark side of politicians' regulation, recent studies show a positive impact of regulation on the business environment. Among those studies, Canare (2018) indicated that the components of starting a business positively affected business creation in 120 countries examined. Additionally, Davari and Farokhmanesh (2017) revealed that legislation positively encouraged the opportunity to start. Farokhmanesh (2017) established that legislation had a positive encouragement effect on startup opportunities. Stel, Storey, and Thurik (2007) found that the minimum capital required to start a business and labour market regulations drop entrepreneurship rates across countries. Musara and Gwaindepi (2014) found that bureaucracy, corruption, policy credibility, policy compliances, and labour restrictions were the topmost factors within the business regulatory environment that distress the process of starting new businesses in South Africa. These researchers also found a positive and significant relationship between bureaucracy and corruption. The more stringent corporate laws could be a hindrance to any overseas investment.

\subsection{Objective of the study}

The main objective of this study is to assess if there are statistically significant improvements in starting a business indicator set since the publication of the WB report on ease of doing business. Specifically, this study examines improvements in the following:

- starting a business score,

- starting a business procedure for men (SBPM),

- starting a business time for men (SBTM),

- starting a business cost for men (SBCM), 
- starting a business procedure for women (SBPW),

- starting a business time for women (SBTW),

- starting a business cost for women (SBCW), and

- starting a business in paid-in minimum capital (SBPMC).

This study contributes to the existing literature by empirically testing to what extent the world has innovated regarding starting business indicators. This study indicates to what extent the world is improving in the business environment. The study supports the publications of the WB's reports on ease of doing business, which lack statistical tests confirming whether there are statistically significant innovations.

\subsection{Research questions}

The business environment is improved when starting a business score is increased. This indicator increases when starting a business score starting a business procedure, time, and costs are reduced. The main research question of this study is as follows:

What innovations are made in starting a business indicator set? The sub-questions of this study are:

- What innovations are made in starting a business score in the world economies?

- What innovations are made in starting a business procedure for men in the world economies?

- What innovations are made in starting a business time for men in the world economies?

- What innovations are made in starting a business cost for men in the world economies?

- What innovations are made in starting a business procedure for women in the world economies?

- What innovations are made in starting a business time for women in the world economies?

- What innovations are made in starting a business cost for women in the world economies?

- What innovations are made in starting a business in paid-in minimum capital in the world economies?

\subsection{Research hypotheses}

Prasad, Rao, and Rehani (2001) identified various meanings of the hypothesis. Accordingly, a hypothesis refers to a conjectural statement of the 
relation between two or more variables. It is a formal statement that indicates the expected relationship between an independent and dependent variable. It can be understood as a tentative explanation of the research problem, an expected outcome, or an educated guess about the research outcome. These authors differentiated the hypothesis from the research question. A research question is a hypothesis requested in the form of a question.

$\mathbf{H}_{0}$ : There are no statistically significant innovations in starting a business indicator set since the publication of the WB report.

$\mathbf{H}_{1}$ : There are statistically significant innovations in starting a business indicator set since the publication of the WB report.

\section{Methods}

\subsection{Data collection}

Data were collected on the WB website (https://www.doingbusiness.org/en/data) to evaluate innovations on starting a business requirement. Making a customer dataset is used to select the required data. (https://www.doingbusiness.org/en/custom-query). This option allowed for selecting indicators and customising the year. Data for the year ended 2004 and 2020 were collected, as the choice of these periods is based on data availability.

The research sample size was calculated using Yamane's (1973) formula with a confidence level of $95 \%$.

$$
\begin{gathered}
\mathrm{n}=\frac{\mathrm{N}}{1+\mathrm{N}(\mathrm{e})^{2}} \\
\mathrm{n}=\frac{213}{1+213(0.05)^{2}}=138.98
\end{gathered}
$$

With $\mathrm{n}=$ sample size required, $\mathrm{N}=$ number of economies in the population, and $\mathrm{e}=$ allowable error (\%). 213 is the number of economies reported in doing business. The sample size was raised to 145 economies to increase the data reliability.

\subsection{Measuring variables}

Data collected are the measures of starting a business score. Starting a business score refers to the simple average of the scores for each component 
indicator: the procedures, time, and cost for an entrepreneur to start and legally work a business, as well as the paid-in minimum capital requirement. These components indicators are defined by the WB as follows:

- Starting a business procedure for men (SBPM): is the number of procedures for men to record all the procedures required in practice for five married male entrepreneurs to start and operate a local limited liability company.

- Starting a business time for men (SBTM): captures the median duration in days that startup experts indicate necessary for five married male entrepreneurs to complete all procedures required to start and operate a business with minimum follow-up and no extra payments. It is calculated in calendar days.

- Starting a business cost for men (SBCM): refers to the total cost required for five married male entrepreneurs to complete the procedures to incorporate and operate a business. It is calculated as a percentage of income per capita.

- Starting a business procedure for women (SBPW): registers all the procedures required in practice for five married female entrepreneurs to start and operate a local limited liability company.

- Starting a business time for women (SBTW): indicates the median days' duration that startup experts indicate is necessary for five married female entrepreneurs to complete all procedures required to start and operate a business with minimum follow-up and no extra payments.

- Starting a business cost for women (SBCW): is the total cost required for five married female entrepreneurs to complete the procedures to incorporate and operate a business. It is calculated as a percentage of income per capita.

- Starting a business in paid-in minimum capital (SBPMC) is the amount the entrepreneur must deposit in a bank or with a third party before registration or up to three months after incorporation. It is calculated as the percentage of income per capita.

\subsection{Data analysis technique}

Two techniques can be used to test whether there is a statistically significant difference in the analysed indicated (paired sample t-test and Wilcoxon signed-rank test). Paired sample t-test is used when the differences for the matched pairs are normally distributed. While Wilcoxon-sign-rank- 
test-paired-sample is used when the differences for the matched pairs are not normally distributed. These tests test the null hypothesis that the actual mean difference is zero. If the true mean difference is zero, no improvement was made from 2004 compared to 2020 on the indicator analysed.

The Wilcoxon signed-rank test evaluates shifts in median values between two groups. This test makes no condition on data distribution and uses the sum of the signed ranks as the test statistic W. The differences of pairs of each indicator were performed using the formula: Difference $=$ Indicator 2020- Indicator 2004.

The Shapiro-Wilk test was used to test the difference in pairs' normality. Kolmogorov-Smirnov, Shapiro-Wilk, and Anderson-Darling tests are among the most general methods used to test normality (Kwak\& Park, 2019). The significance level considered was 5\%. If the probability value (pvalue) is less than .05 , the null hypothesis of normality is rejected. The result of the Shapiro test Wilk showed that differences for the matched pairs were not normally distributed. Therefore, Wilcoxon-sign-rank-test-paired-sample was used instead of paired t-test.

The distribution of the difference for each pair of indicators was tested using the Shapiro-Wilk test to decide between the paired sample t-test and the paired sample Wilcoxon test. Paired sample t-test, a parametric test, is used when the distribution of differences is approximately normal. When differences are not normally distributed, the paired-samples Wilcoxon test is used. Because it is difficult to draw accurate conclusions if they do not hold, Ghasemi and Zahediasl (2012) indicated that normality and other hypotheses should be taken seriously. Nevertheless, these authors added that the breach of the normality principle does not trigger major problems with large enough sample sizes ( $>30$ or 40 ); we can use parametric procedures even though the data are not normally distributed. Kwak and Park (2019) indicated that when the number of samples exceeds 30 , the mean sample distribution satisfies the normal distribution, according to the central limit theorem. R programming environment was used to test the normality of pairs of differences. JASP was used to compute Wilcoxon signed-rank test and effect size.

\section{Result and discussion}

Before proceeding with the data analysis, descriptive statistics are presented; tables 1 to 3 present central tendency (mean and median), which shows the tendency of the analysed indicators. The same Tables also give the measure of dispersion, indicating how data deviate from the mean. The standard deviation is a kind of average of these deviations from the mean. It is the square root of the sum of squared deviations divided by the number of 
observations. Mishra et al. (2019) showed that skewness and Kurtosis could be used to test normality. According to them, skewness assesses symmetry, or lack of symmetry, of the normal distribution, while Kurtosis appraises the peakedness of a distribution.

Table1. Descriptive statistics of SBS, SBPM, and SBTM

\begin{tabular}{lllllll}
\hline & SBS2020 & SBS2004 & SBPM2020 & SBPM2004 & SBTM2020 & SBTM2004 \\
\hline Valid & 145 & 145 & 145 & 145 & 145 & 145 \\
Mean & 84.256 & 60.494 & 6.552 & 10.317 & 20.541 & 52.686 \\
Median & 86.900 & 62.900 & 6.000 & 11.000 & 12.000 & 42.000 \\
Standard deviation & 11.869 & 20.857 & 3.002 & 3.429 & 28.299 & 40.356 \\
Skewness & -1.974 & -0.534 & 0.839 & -0.013 & 4.425 & 1.972 \\
Kurtosis & 5.701 & -0.381 & 1.733 & -0.066 & 26.033 & 5.385 \\
Minimum & 25.000 & 11.600 & 1.000 & 2.000 & 0.500 & 3.000 \\
Maximum & 100.000 & 96.200 & 20.000 & 20.000 & 230.000 & 260.000 \\
\hline
\end{tabular}

Source: Author's calculation using WB indicator data

Table 2. Descriptive statistics of SBCM, SBPW, and SBTW

\begin{tabular}{lllllll}
\hline & SBCM2020 & SBCM2004 & SBPW2020 & SBPW2004 & SBTW2020 & SBTW2004 \\
\hline Valid & 145 & 145 & 145 & 145 & 145 & 145 \\
Mean & 19.971 & 101.431 & 6.648 & 10.414 & 20.638 & 52.783 \\
Median & 6.700 & 28.000 & 6.000 & 11.000 & 12.000 & 42.000 \\
Standard & 36.157 & 223.862 & 3.015 & 3.511 & 28.309 & 40.376 \\
deviation & 3.529 & 4.833 & 0.798 & 0.014 & 4.415 & 1.968 \\
Skewness & 13.558 & 26.522 & 1.575 & -0.041 & 25.937 & 5.366 \\
Kurtosis & 0.000 & 0.000 & 1.000 & 2.000 & 0.500 & 3.000 \\
Minimum & 211.800 & 1540.200 & 20.000 & 20.000 & 230.000 & 260.000 \\
Maximum & & &
\end{tabular}

Source: Author's calculation using WB indicator data

There is asymmetric distribution if a distribution's mean, median, and mode coincide. The skewness for normally distributed data is near 0 , while Kurtosis should be around 3. The minimum and maximum values for each indicator are presented. 
Table 3. Descriptive statistics of SBCW and SBPMC

\begin{tabular}{lllll}
\hline & SBCW2020 & SBCW2004 & SBPMC2020 & SBPMC2004 \\
\hline Valid & 145 & 145 & 145 & 145 \\
Mean & 19.974 & 101.432 & 5.560 & 192.916 \\
Median & 6.700 & 28.000 & 0.000 & 29.200 \\
Standard deviation & 36.157 & 223.863 & 18.864 & 526.991 \\
Skewness & 3.529 & 4.833 & 6.575 & 6.427 \\
Kurtosis & 13.557 & 26.522 & 53.375 & 53.820 \\
Minimum & 0.000 & 0.000 & 0.000 & 0.000 \\
Maximum & 211.800 & 1540.200 & 179.600 & 5109.400 \\
\hline
\end{tabular}

Source: Author's calculation using WB indicator data

Table 4 shows the results of the normality test. As indicated, this test allows choosing between paired sample t-test (parametric) and Wilcoxon signed-rank test (nonparametric). As can be seen, at a significant level of 5\%, only SBPW is normally distributed. However, the p-value of 0.068 is far from the significance level. In other words, the differences in paired observations are not normally distributed. Therefore, the Wilcoxon signed-rank test can be applied to test the innovations made for each indicator under analysis.

Table 4. Test of normality (Shapiro-Wilk)

\begin{tabular}{|c|c|c|c|}
\hline & & W & $\mathrm{p}$ \\
\hline SBS2020 & - $\quad$ SBS2004 & 0.978 & 0.021 \\
\hline SBPM2020 & - $\quad$ SBPM2004 & 0.981 & 0.037 \\
\hline SBTM2020 & - $\quad$ SBTM2004 & 0.869 & $<0.001$ \\
\hline SBCM2020 & - $\quad$ SBCM2004 & 0.453 & $<0.001$ \\
\hline SBPW2020 & - $\quad$ SBPW2004 & 0.983 & 0.068 \\
\hline SBTW2020 & - $\quad$ SBTW2004 & 0.869 & $<0.001$ \\
\hline SBCW2020 & - $\quad$ SBCW2004 & 0.453 & $<0.001$ \\
\hline SBPMC2020 & - $\quad$ SBPMC2004 & 0.378 & $<0.001$ \\
\hline
\end{tabular}

Source: Author's calculation using WB indicator data

To assess if there is a statistically significant change in starting business components after the WB's ease of doing business publication, a Wilcoxon Signed Rank test was used. Table 5 presents the results of the Wilcoxon Signed Rank test. It also presents the effect of the difference. The Hodges-Lehmann estimate's location parameter is the median difference between the two groups. The rank-biserial correlation (rB) can be considered an effect size measuring how important a difference is and is interpreted the same as Pearson's $r$ as the effect size is greater than 0.7 for all indicators. It 
means that the effect size is large. In other words, the difference between the 2004 and 2020 scores is large, indicating significant innovations in reducing starting a business burden.

Table 5. Wilcoxon signed-rank test

\begin{tabular}{llllll}
\hline Measure 1 & Measure 2 & W & $\mathrm{p}$ & $\begin{array}{l}\text { Hodges-Lehmann } \\
\text { estimate }\end{array}$ & $\begin{array}{l}\text { Rank-biserial } \\
\text { correlation }\end{array}$ \\
\hline SBS2020 & - SBS2004 & 10155.000 & $<0.001$ & 23.050 & 0.919 \\
SBPM2020 & - SBPM2004 & 655.000 & $<0.001$ & -4.000 & -0.859 \\
SBTM2020 & - SBTM2004 & 743.000 & $<0.001$ & -28.500 & -0.854 \\
SBCM2020 & - SBCM2004 & 1131.500 & $<0.001$ & -33.050 & -0.783 \\
SBPW2020 & - SBPW2004 & 659.000 & $<0.001$ & -4.000 & -0.854 \\
SBTW2020 & - SBTW2004 & 766.000 & $<0.001$ & -28.000 & -0.851 \\
SBCW2020 & - SBCW2004 & 1131.500 & $<0.001$ & -33.050 & -0.783 \\
SBPMC2020 & - SBPMC2004 & 89.500 & $<0.001$ & -122.450 & -0.965 \\
\hline
\end{tabular}

Source: Author's calculation using WB indicator data

To assess if there are statistically significant innovations in starting a business score (SBS), a Wilcoxon Signed Rank test indicated that the median for 2020 , Mdn $=86.9$, was statistically significantly higher than the median for 2004, $\mathrm{Mdn}=62.9, \mathrm{~W}=10155, \mathrm{p}<0.001$. The effect size is 0.919 is positive and significant.

To assess if there are statistically significant innovations in the starting a business procedure for men (SBPM), a Wilcoxon Signed Rank test indicated that the median for 2020, $\mathrm{Mdn}=6$, was statistically significantly less than the median for $2004, \mathrm{Mdn}=11, \mathrm{~W}=655, \mathrm{p}<0.001$. The effect size is -0.859 is negative and significant.

To assess if there are statistically significant innovations in starting a business time for men (SBTM), a Wilcoxon Signed Rank test indicated that the median for $2020, \mathrm{Mdn}=12$, was statistically significantly less than the median for $2004, \mathrm{Mdn}=42, \mathrm{~W}=743, \mathrm{p}<0.001$. The effect size is -0.854 is negative and significant.

To assess if there are statistically significant innovations in the starting a business cost for men (SBCM), a Wilcoxon Signed Rank test indicated that the median for $2020, \mathrm{Mdn}=6.7$, was statistically significantly less than the median for 2004, $\mathrm{Mdn}=28, \mathrm{~W}=1131.5, \mathrm{p}<0.001$. The effect size is -0.783 is negative and significant.

To assess if there are statistically significant innovations in starting a business procedure for women (SBPW), a Wilcoxon Signed Rank test indicated that the median for $2020, \mathrm{Mdn}=6$, was statistically significantly less than the median for 2004, $\mathrm{Mdn}=11, \mathrm{~W}=659, \mathrm{p}<0.001$. The effect size is -0.854 is negative and significant. 
To assess if there are statistically significant innovations in starting a business time for women (SBTW), a Wilcoxon Signed Rank test indicated that the median for 2020 , Mdn $=12$, was statistically significantly less than the median for $2004, \mathrm{Mdn}=42, \mathrm{~W}=766, \mathrm{p}<0.001$. The effect size is -0.851 is negative and significant.

To assess if there are statistically significant innovations in starting a business cost for women (SBCW), a Wilcoxon Signed Rank test indicated that the median for $2020, \mathrm{Mdn}=6.7$, was statistically significantly less than the median for 2004, Mdn $=28, \mathrm{~W}=1131.5, \mathrm{p}<0.001$. The effect size is 0.783 is negative and significant.

To assess if there are statistically significant innovations in starting a business in paid-in minimum capital (SBPMC), a Wilcoxon Signed Rank test indicated that the median for $2020, \mathrm{Mdn}=0.00$, was statistically significantly less than the median for 2004, $\mathrm{Mdn}=29.2, \mathrm{~W}=89.5, \mathrm{p}<0.001$. The effect size is -0.965 is negative and significant.

This analysis indicated that countries made many innovations to improve their business environment. Starting a business indicator was improved worldwide, which is a good sign of innovation in doing business environment. The results reveal that the procedures and time required for men to start a business have been reduced. It was found that the cost for men to start a business was reduced. The results indicate that the time and cost to start a business for women have been reduced. Finally, it was found that the paid-in minimum capital has been reduced since 2004 .

Improving the business environment would lead to positive economic spillovers. For instance, Canare (2018) indicated that starting a business component positively affected business creation in 120 countries examined. Davari and Farokhmanesh (2017) stated that legislation positively encouraged startup opportunities.

Regarding minimum capital to start, Stel, Storey, and Thurik (2007) found that the minimum capital requirement required to start a business and labour market regulations drop entrepreneurship rates across countries. Musara and Gwaindepi (2014) concluded that bureaucracy, corruption, policy credibility, policy compliances, and labour restrictions were the topmost factors within the business regulatory environment that distress the process of starting new businesses in South Africa. These researchers also found a positive and significant relationship between bureaucracy and corruption. The more stringent corporate laws could be a hindrance to any overseas investment. On the other hand, a company climate that is notably devoid of laws may be less appealing to prospective investors and more vulnerable to malpractices. Mottaleb and Kalirajan (2010) state that a more businessfriendly environment attracts foreign direct investment. 


\section{Conclusion}

This study evaluates the innovations made by economies to reduce starting business requirements. It empirically demonstrates the significance of the innovations to support the ease of starting a business. The Wilcoxon Signed Rank test results show that the starting a business score has significantly increased. The component of this indicator, such as starting a business procedure for men, starting a business time for men, starting a business cost for men, starting a business procedure for women, starting a business time for women, starting a business cost for women, and starting a business in paid-in minimum capital has been significantly decreased. The results allow us to reject the null hypothesis indicating that there are no statistically significant innovations in starting a business indicator set since the publication of the WB. Therefore, the alternative hypothesis was confirmed that there are statistically significant innovations in starting a business indicator set since the publication of the WB in 145 economies examined. This study empirically validates the claims of the WB (2020) that most of the reforms addressed aspects of starting a business, dealing with construction permits, getting electricity, and paying taxes. The study revealed that the effect size of changes was significant.

\subsection{Theoretical implications}

Since 2003, the WB has evaluated economies based on ten areas that are supposed to impact the business environment. Annually, the WB produced a report of the regulatory reforms made by each economy in the doing business report since that period. Nevertheless, no study has been conducted to investigate empirically to what extent the regulatory reforms were statistically significant. This study contributes to the existing literature by evaluating and demonstrating the extent and significance of the regulatory reforms since 2004. Transaction cost theory suggests that business transactions incur costs like discussing contracts, monitoring performance, and solving disputes. Different modes of organising businesses involve various costs (Rindfleisch, 2019). Therefore, economies have tried to reduce the cost of starting a business.

\section{2. practical implications}

This study has practical implications regarding improving the business environment. Reducing starting a business cost can reduce corruption and increase formal business. Djankov, La Porta, Lopez-De- 
Silanes, and Shleifer (2002) concluded that most countries' official entry costs were extremely high. Moreover, countries with heavier regulation of entry had higher corruption and larger unofficial economies, nonetheless, the not better quality of public or private goods. This can contribute to the increase in the number of newly registered businesses. Opportunities for starting a new business are supposed to increase, as Farokhmanesh (2017) hypothesised that legislation had a positive encouragement effect on the opportunity to startup. Chambers and Munemo (2019) established a negative correlation between procedures and new business creation. They indicated that entrepreneurial activity decreased between three and seven per cent when the number of steps required to create a new business increased by unit. The productivity of companies is predicted to increase. This idea is supported by the WB (2020) by indicating that improving firm entry regulation was correlated with higher productivity.

\subsection{Limitation of the study}

The WB indicated that more than 3,800 business regulatory reforms had been realised across the 190 economies measured by doing business since 2005. Additionally, most reforms addressed starting a business, dealing with construction permits, getting electricity, and paying taxes. This study evaluated whether business regulations implemented regarding starting a business were statically significant. Future research should be conducted to test the significance of the implemented procedures related to other indicators evaluated in doing business reports. These indicators include dealing with construction permits, getting electricity, registering property, getting credit, protecting minority investors, paying taxes, trading across borders, enforcing contracts, and resolving insolvency.

\section{Declaration of conflicting interests}

The author(s) declared no potential conflicts of interest with respect to the research, authorship, and/or publication of this article.

\section{References}

Buckley, P. J. \& Casson, M. C. (2009). The internalisation theory of the multinational enterprise: a review of the progress of a research agenda after 30 years. Journal of International Business Studies, 40, 1563-1580. https://doi.org/10.1057/jibs.2009.49

Canare, T. (2018). The effect of ease of doing business on firm creation. Annals of Economics and Finance 19(2), 555-584. https://doi.org/10.1080/13571510110051504 
Cantwell, J. \& Narula, R. (2001). The eclectic paradigm in the global economy. Int. J. of the $\begin{array}{lllll}\text { Economics of } & \text { Business, } & 8 & \text { (2). }\end{array}$ https://doi.org/10.1080/13571510110051504

Chambers, D. \& Munemo, J. (2019). Regulations, institutional quality and entrepreneurship. International Journal of Energy Economics and Policy 11(2),133-140, https://doi.org/10.32479/ijeep.10584

Davari, D. \& Farokhmanesh, J. (2017). Regulations, institutional quality and entrepreneurship. Journal of Regulatory Economics, 55(1).

Djankov, S., La Porta, R., Lopez-De-Silanes, F., \& A. Shleifer. (2002). The regulation of entry. The Quarterly Journal of Economics,117 (1), 137.https://doi.org/10.1162/003355302753399436

Etzioni, A. (2009). The capture theory of regulations-revisited. Society,46, 319-323. https://doi.org/10.1007/s12115-009-9228-3

Goss-Sampson, M. A. (2018). Statistical analysis in JASP. A guide for students. https://static.jaspstats.org/Statistical\%20Analysis $\% 20 \mathrm{in} \% 20 \mathrm{JASP} \% 20 \% 20 \mathrm{~A} \% 20 \mathrm{St}$ udents\%20Guide\%20v1.0.pdf

Holcombe, R. G. (2018). Checks and balances: enforcing constitutional constraints. Economies, 6(4), 57.https://doi.org/10.3390/economies6040057

Juan, M. R. J., Raquel, F. L., \& Pedro, A. P. (2019). Resource-based view and SMEs performance exporting through foreign intermediaries: the mediating effect of management controls. Sustainability, 11(12), 3241.https://doi.org/10.3390/su11123241

Kwak, S. G. \& S. H. Park. (2019). Normality test in clinical research. Journal of Rheumatic Diseases, 26(1), 5-11. https://doi.org/10.4078/jrd.2019.26.1.5

Martins, R. A., Serra, F. R., Leite, A. S., Ferreira, M. P., \& Li, D. (2010). Transactions cost theory influence in strategy research: a review through a bibliometric study in leading journals. http://www.anpad.org.br/admin/pdf/eso82.pdf

Mishra, V., Khanra, D., Himanshu, K., Jain, B., Tripathi, S., Aggarwal, P., Soni, S., Kumar Reddy, N., Singla, R., Mishra, M., \& Sinha, S. (2019). Descriptive statistics and normality tests for statistical data. Annals of Cardiac Anaesthesia, 22(1), 67-72. https://doi.org/10.4103/aca.aca_157_18

Mottaleb, K.A. \& Kalirajan, K. (2010). Determinants of foreign direct investment in developing countries: a comparative analysis. The Journal of Applied Economic Research 4 (4), 369-404. https://doi.org/10.1177/097380101000400401

Musara, M. \& Gwaindepi, C. (2014). Factors within the business regulatory environment affecting entrepreneurial activity in South Africa. Mediterranean Journal of Social Sciences, 5(6), 109-116. https://doi.org/10.5901/mjss.2014.v5n6p109

Myung, K.Y. \& Choi, Y.H. (2017). The influences of leaders' dark triad trait on their perception of CSR. Asian Journal of Sustainability and Social Responsibility, 2, 721.https://doi.org/10.1186/s41180-017-0013-8

Olagunju, O.O. \& J.O. Ikeolumba. (2019). The evaluation of the national policy on ease of doing business in Nigeria. European Scientific Journal,15 (8), 203212.https://doi.org/10.19044/esj.2019.v15n8p203

Prasad, S., Rao, A. \& Rehani, E. (2001). Developing hypothesis and research questions. https://www.public.asu.edu/ kroel/www500/hypothesis.pdf

Rindfleisch, A. (2019). Transaction cost theory: past, present and future. Academy of 
Marketing Science Review.10(1-2), 85-97.https://doi.org/10.1007/s13162-019-00151-x

Stel, A.V., Storey, D.J. \& Thurik, A.R. (2007). The effect of business regulations on nascent and young business entrepreneurship. Small Business Economics, 28(2),171-186 . https://doi.org/10.1007/s11187-006-9014-1

World Bank Group. (2020). Doing Business 2020. https://doi.org/10.1596/978-1-4648-14402 